\title{
Lower Back Pain
}

National Cancer Institute

\section{Source}

National Cancer Institute. Lower Back Pain. NCI Thesaurus. Code C34788.

A sensation of discomfort emanating from the lower back. 